\title{
Chapter 2 \\ Drawing as a Salutogenic Therapy Aid for Grieving Adolescents
}

\author{
Masego Katisi, Philip Jefferies, and Mpho Sebako
}

\subsection{Introduction}

Drawing can improve sensory motor skills, encourage the use of imagination, help to develop creativity, and above all presents a fun and enjoyable pastime (Vendeville et al. 2018). However, beyond play and skill development, it is an important method of communication and a tool for exploring complex and difficult issues, which may be more challenging with younger individuals (Pifalo 2007; Ugurlu et al. 2016). Drawing can also assist as a therapeutic aid in the identification of pathways to good health and well-being, such as enabling young people to map and reflect on their local supportive resources, in turn enabling a more positive reappraisal of their situation (Campbell et al. 2010; Campbell et al. 2015). The first chapter of this volume (see Chap. 1), describes the potential for the Arts and health promotion in a broad treatment, this chapter focuses specifically on the salutogenic qualities of drawing.

\footnotetext{
M. Katisi $(\square)$

Western Norway University of Applied Sciences, Faculty of Health and Social Sciences, Bergen, Norway

e-mail: Masego.Katisi@hvl.no

P. Jefferies

Resilience Research Centre, Faculty of Health, Dalhousie University, Halifax, NS, Canada e-mail: philip.jefferies@dal.ca

M. Sebako

Ark and Mark Trust, Gaborone, Botswana

e-mail: msebako@arkandmark.org
} 


\subsection{The Context}

In sub-Saharan Africa, the scourge of HIV/AIDS causes over 380,000 deaths per year. The infection rate in the region continues to increase, and UNAIDS records that 18.7 million (half of the HIV/AIDS infected population) live in East and Southern Africa (UNAIDS 2019). Many children have watched their parents suffer through this debilitating illness, and many have also witnessed their final moments. In addition to the trauma caused by the death of a parent, many of these children also experience subsequent challenges like stigma, poverty, abuse (sexual, emotional, and/or physical), and relational and educational issues (Meissner et al. 2017; Thamuku and Daniel 2013; Wakhweya et al. 2008; Xiaoming et al. 2015).

In a review of studies exploring the mental health of children affected by HIV/ AIDS in sub-Saharan Africa, Skovdal (2012) determined that the majority focused on distress and reports of stress and depression, which were related to the burden of caring for ailing parents and the need to look after younger siblings (Cluver et al. 2007; Toska et al. 2016). However, clinicians who focus on distress risk pathologizing children's social experiences, and others have established that activities such as caring for others and performing home chores are seen by affected children as good training and competence building (Daniel et al. 2007; Skovdal and Daniel 2012). Thus, an alternative perspective that focuses on the strengths and positive supports despite adversity can elucidate social and psychological pathways to resilience.

Furthermore, while many interventions have been established to support orphaned children in Africa (Deininger et al. 2003; Heath et al. 2014; Schenk 2009; Strebel 2004), there is a lack of knowledge exploring how drawing could be used in these settings as an additional tool to help children process their grief and other challenges they have experienced and continue to experience (Thamuku and Daniel 2013), and also how drawing may be used to identify the support and resources children can draw on to build and maintain their resilience.

\subsection{Theoretical Framework}

This study uses the Sense of Coherence (SOC) from the salutogenic framework of health promotion to explore the use of drawings by grieving adolescents in Botswana. Antonovsky (1996) describes SOC as a global orientation that derives from one's confidence that both internal and external environments are predictable, resources are available, and problems are simply challenges worthy of investment and engagement. An individual's SOC is divided into three parts, each on a continuum (Fig. 2.1). The first is comprehensibility, meaning that one comprehends or evaluates their life situation as understandable and resolvable. The second component is manageability, which is the extent to which one believes that the resources around them can help address their life stressors. The third component is meaningfulness, which is a motivational component describing one's positive emotional 


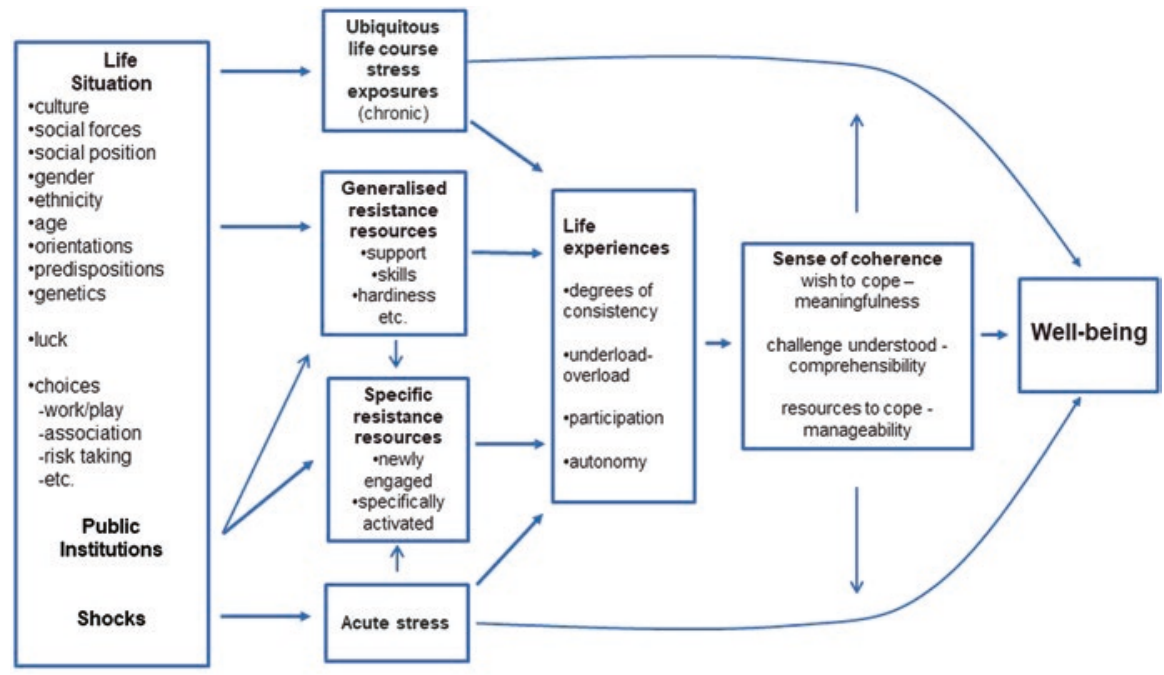

Mittelmark MB (2013). Resources for Health in the Salutogenic Model: Specific Resistance Resources contra Generalised Resistance Resources in the Context of Health Promotion Practice and Research. Nethenlands Congres Volksgezondheid 2013, 3 April, 2013

Fig. 2.1 The salutogenic model of health and sense of coherence. (Adapted from Mittelmark 2013, with permission from Antonovsky)

tendencies toward their life situation. It means believing that things make sense and that one's actions in relation to their situation can make things better.

As is shown in Fig. 2.1, SOC links with the availability of resources (termed Generalized Resistance Resources, or GRR) (Mittelmark and Bull 2013). GRRs strengthen one's SOC, and a strong SOC influences the ability to manage one's life situation and move toward health (Antonovsky 1996). Reciprocally, a stronger SOC helps individuals to navigate and negotiate for these GRRs (Mittelmark 2017) and to address their challenges and move toward health. When one has a strong SOC, that individual is likely to be able to confront and manage challenges more effectively (Mittelmark 2017; Mittelmark and Bull 2013).

The role of SOC in supporting people's movement toward health has been investigated by researchers across many life settings (Darkwah et al. 2017; Jellesma et al. 2006; Løndal 2010; Mayer and Krause 2011; Nammontri et al. 2013; Ray et al. 2009). For instance, Elfassi et al. (2016) found that adolescents' coping capacities shift from mainly depending on primary external-behavior-oriented sources of support to their internal capacities. However, they acknowledged that regardless of adolescents' growing cognitive strength, the availability of resources in and around the home environments still remain key in helping them see life challenges as more comprehensible, manageable, and meaningful. Similarly, Braun-Lewensohn et al. (2017) reviewed studies of SOC in childhood and families, finding that predictors of children's psychosomatic complaints were mostly related to resources in their environment, including ill health of mothers, weak social relations with peers, and 
unsupportive school environments. Both internal and external resources are therefore key in enhancing children's SOC.

\subsection{The Intervention: Balekane EARTH}

This study is part of a larger project exploring the effectiveness of the Balekane EARTH program in Botswana. "Balekane" is a Botswanan/Setswana word for the participants of the program, meaning "age-mates," and EARTH is an acronym for Empathy-based, Action-orientated, Relationship-building, Transformative, Healing therapy. The program is designed to offer psychosocial treatment and support for adolescents aged 12-15 who have experienced significant trauma (most often the loss of parent(s) due to HIV/AIDS). The program initially runs for 14 days at wilderness camps where young people engage in individual and group therapy. The camps are organized in such a way that therapy is complemented by team building activities through the use of high and low ropes challenge courses; enactment of rites of affirmation to mark group and individual progress; and safari drives to learn about animal behavior and apply reflectively to own behaviors. The program then continues for 3 years with services provided to the participants back in their home communities. Further information about the program can be found in Katisi et al. (2019).

During the camps, at about halfway through the therapy sessions, drawings are introduced together with written and verbal narration to help the young people process their grief. Individual-focused narrative therapy about the drawings and the experience of the drawing process then follows. The sessions conclude with group narrative therapy in the final days of the camp. The therapies involving the drawings focus on both what the child has drawn and constructive resolutions about challenges that the drawings and the drawing process indicate.

\subsubsection{Method}

The art therapy workbook used for eliciting drawings was an adapted version of Margie Heegaard's When Someone Very Special Dies: Children Can Learn to Cope with Grief (Heegaard 1996). This locally adapted workbook was given the title Grieving Someone Special and consists of 25 pages of prompts for content, including sketching, coloring, and sometimes writing. For instance, one page reads: "Life is full of changes: There have been a lot of changes where I live. Draw or write to show a change that concerns you the most." Another reads: "People in the community participate in funerals. This is what they do." Another prompts: "Different feelings are allowed. Sometimes I feel..."

When engaging with the workbook, participants sit alone under a tree of their choice and draw in peace under non-intrusive supervision. After completion, they 
discuss their drawings and drawing experience privately with their social workers. When they are ready, they share some of their experiences and discuss strategies to resolve difficulties as a group.

The drawings in this chapter come from 15 adolescents aged 12-15 years who selected pictures they were happy for us to share. We analyzed these drawings as well as others in their workbook along with their written and verbal narrations. Their data was complemented by two young adults, aged 22 and 25, who completed the program when they were 18 and were willing to share their stories. The participants also took part in focus group discussions at the end of the camps, and we include some content from these discussions in our analysis of the drawings. Further insight comes from interviews with, and observations from, four social workers who undertook the therapy with the participants.

\subsubsection{Data Analysis}

To analyze the data (including drawings, captions, narrations, and other sources of information), we used thematic content analysis (Attride-Stirling 2001). We utilized a hybrid approach by first deductively drawing codes from the data that linked to qualities associated with an SOC, and then inductively abstracting basic themes, organizing themes, and global themes. The first author (MK) performed the analysis, which then involved the social workers affirming that the themes were appropriate representations (i.e., member checking).

Our analysis is structured around the concepts of comprehensibility, manageability, and meaningfulness from the salutogenic model. These three concepts are interlinked and not easily separable as stand-alone themes. However, in the salutogenic framework above, the "life course stress exposures" and "generalized resistance resources" are more concrete and distinguishable when describing participants' situations. We therefore categorized these descriptions using three global themes: (1) stressors, (2) resources, and (3) strategies. It is also important to note that the participants conveyed painful experiences, resources, resolutions, and hope in mixed and overlapping ways. Lastly, we identified global themes as a whole using the SOC concepts of comprehensibility, manageability, and meaningfulness.

Ethical approval for this research was granted by Botswana's Ministry of Local Government. We acquired written consent from participants, social workers, and caregivers, which was provided in the weeks prior to the wilderness camps and included permission to publish drawings. Pseudonyms were used to maintain confidentiality, and identifying details (like names) were removed from the drawings. As the participants were recounting painful memories, we ensured these discussions took place in a therapeutic environment where they had access to qualified professional support. 


\subsection{Findings}

\subsubsection{Stressors}

The drawings that the participants shared indicated different challenging issues that seemed to be ongoing stressors in their lives. These stressors included witchcraft, sudden death, death due to illness, suicide, and poverty.

\subsubsection{Witchcraft}

Several of the participants reported that witches tormented them, both in dreams and in waking life. Some described their belief that the reason their parents got sick and died was because they (parents) were bewitched. For example, the drawing below (Fig. 2.2) was created by Leila, a 15-year-old girl, under the prompt asking, "What happens during funerals?" The witches, drawn wearing black church clothes, were neighbors who were also members of the church and involved in conducting the funeral. Leila expressed that these three neighbors were too controlling during the funeral, instructing the family on how and where the burial should be and being involved in family rituals. During individual and group therapy, Leila explained that

Balelwapa le ditsala ba phutega mmogo go rulaganya le go dira phitlho, go tlotla yo o thokafetseng, go gakologelwa tse di molemo tse di dirileng, le go supa lorato mo go yo o thokafaletsweng.

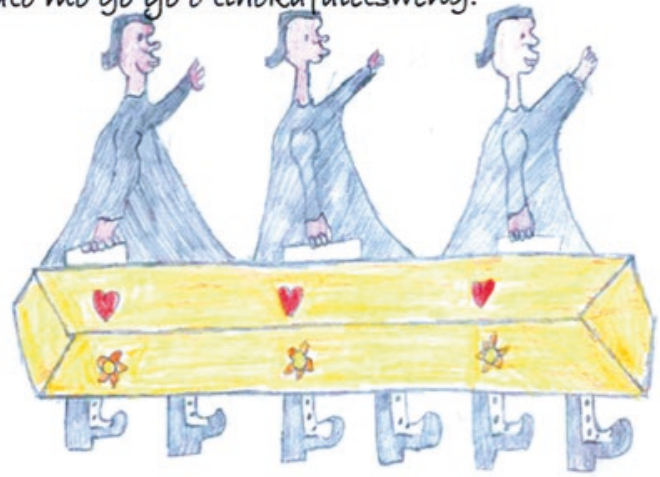

Go thata/bokete go laela motho yo o mo ratang!

Fig. 2.2 Leila's depiction of witchcraft (the caption reads: "During the funeral, relatives and friends gather together to arrange for burial."). (Reproduced with permission from Ark and Mark Trust, Botswana. Copyright (C) 2021 Ark and Mark Trust. All rights reserved) 
her family told her that the witches later dug up and took away the casket from the graveyard and that no one could return it. This was something that caused her great distress, as she felt that she could not visit her mother's "empty" grave. She felt like she lost her mother twice.

During the focus groups, Leila explained that the three hearts and flowers on the casket were her own expressions of love toward her mother. She used these symbols to depict her feelings but also to explain that her love moved together with her mother's body, wherever the witches took it. She remained concerned and upset about not knowing where her mother had been taken. Leila also struggled to complete the picture, skipping to different pages before returning to the picture to continue. At one point she abandoned the workbook, appearing tense, and requested a break. She later shared her feelings about drawing during focus group discussions: "I felt scared again by the witches. I don't know them exactly, but I guess they are...some of our neighbors. ...It was hard. I was able to talk about it [the picture] during group discussions after talking for a long time with my social worker. It was...not easy before..."

\subsubsection{Sudden Death}

The participants used drawings to express love, a sense of oneness with their late parents, and expressions of shock. The latter was related to unexpected death, even in cases where the adolescents were aware that their parents were sick. In some drawings, color and the positioning of figures indicated experiences of trauma that still lingered. Several participants drew themselves as comparably small figures and at a distance away from the body of the parent when expressing sudden deaths.

Tracy, a 14-year-old girl who lost her mother unexpectedly, explained that her picture reflected her shock and helplessness, which she continued to feel. Her drawing portrays herself viewing her mother's corpse (Fig. 2.3). When asked why she drew herself with no hands, she said, "In this picture, I am holding my hands behind. You cannot see them. I hold my hands back when I do not know what to do. I am shocked here, you see...my mother died... suddenly." Like Leila, Tracy decorated the blanket covering her late mother with flowers. She explained that the flowers demonstrated her love for her mother. In another drawing, she drew and described taking flowers to her mother's grave, particularly on occasions when she was mistreated at home. She colored herself and her mother with similar colors because it showed they are one and they need each other. She also explained that the line in between them is a curtain that was in the house when she viewed her corpse, a symbol of separation.

Like Leila and others, Joseph (age 17) drew himself and his late mother quite small on the page (Fig. 2.4). When asked about this, he explained that smallness was an expression of confusion, shock, and immense helplessness. "I felt like nobody," he said. It is important to note that not every detail or characteristic is symbolic or representative of something. For example, when asked about his use of colors, Joseph said that there was no particular reason for this choice. 


\section{Mo go bot lhe ba losika ba ba suleng, yo o neng a le bot lhokwa thata mo go nna}

ke

Setshwantsho se, se supa ka fa a thokafetseng ka teng, ka fa go nkamileng ka teng.

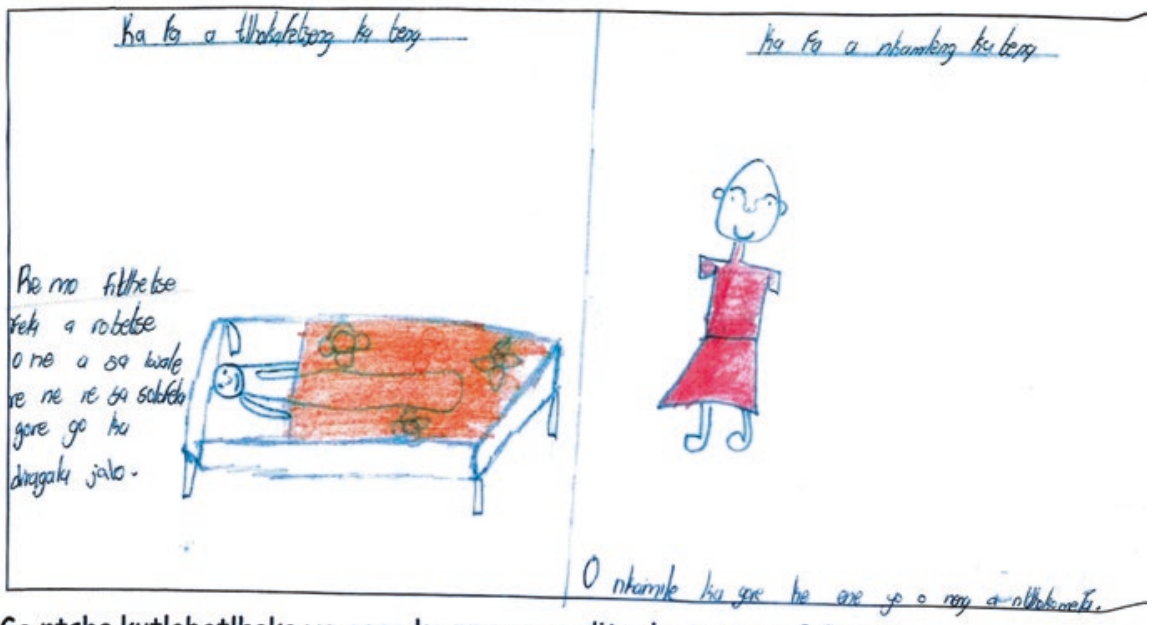

Go ntsha kutlobotlhoko ya gago ke nngwe ya ditsela tsa go e fokotsa.

Fig. 2.3 Tracy's depiction of the sudden death of her mother (the caption reads: "Among all that have died, the most important person was...my mother. She just died in sleep. She was not ill... This hurt me the most...she was the only one taking care of us."). (Reproduced with permission from Ark and Mark Trust, Botswana. Copyright $(\subseteq 2021$ Ark and Mark Trust. All rights reserved)

The social workers reported that many participants who lost their parents saw them deteriorate daily. Several of them expressed that it was painful to watch their parents-some of whom experienced excruciating pain-struggling with their sickness. One participant explained that they used to sneak out from school to check on their ailing mother at home. The children felt fear and helplessness, and this lingered with them long after the passing of their parents.

Peter (Fig. 2.5) was a 15-year-old participant who appeared particularly traumatized by the sudden death of his mother. He said, "I cry. I cry always. They say a boy is not supposed to cry but I cry a lot. It scares me to have these thoughts. It is because I want to see my mother. I want her to help me. I cry when I think like this. See, my tears are like rain..." Peter cried a lot during the early sessions, but the social workers suggested that he seemed happier afterwards. During focus group discussions, Peter said, "I do not cry a lot now. I talked a lot. Maybe I need to talk a lot so that I don't cry a lot. I need help from someone else. I realize my late mother cannot help."

Crying seemed to trigger crying. One social worker shared that others in the group cried when they saw others cry. "During this session, one child started crying when sharing her story. One more followed and suddenly almost all were crying except for a few boys. We had to end the session after everyone felt relieved... They 
Mo go botlhe ba losika ba ba suleng, yo o neng a le botlhokwa thata mo go nna ke Setshwantsho se, se supa ka fa a thokafetseng ka teng, ka fa go nkamileng ka teng.

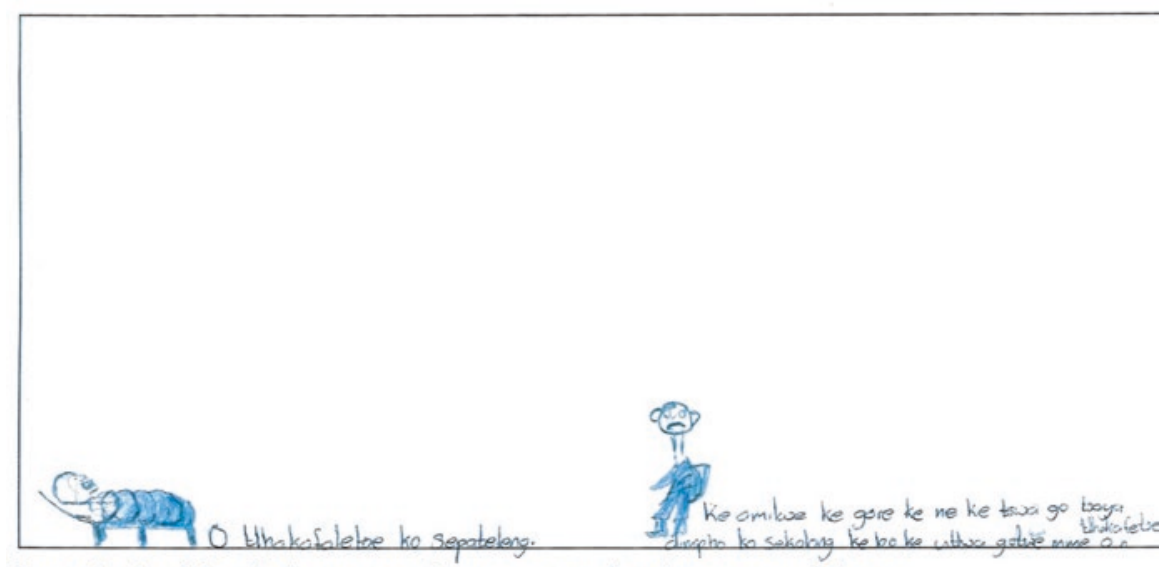

Go ntsha kutlobotlhoko ya gago ke nngwe ya ditsela tsa go e fokotsa.

Fig. 2.4 Joseph's depiction of his mother's death (the caption reads: "She died at the hospital. What hurts me the most is that I was told of her death the same day I got presents for doing well at school."). (Reproduced with permission from Ark and Mark Trust, Botswana. Copyright (C 2021 Ark and Mark Trust. All rights reserved)

preferred not to share any more of their stories until the following day. Crying gave them a relief, then they were ready to share more experiences the following day."

\subsubsection{Ghosts and the Dead}

One 13-year-old boy, Thomas, simply wrote, "You cannot help me..." He did not draw any pictures in his workbook and instead wrote long narrations about a "thokolosi" (ghost) that visited him all night and tormented him. He explained how this caused him difficulties in school. He described the thokolosi as hairy and animalistic in figure and movement. In his dreams, it always opened its mouth wide to scare him. He believed the thokolosi was a figure representing an angry dead relative. When asked why he did not draw the thokolosi, he exclaimed, "No, I can't draw it. It would come to life.... No, I can't. It will scare me.” Other participants also feared drawing figures related to trauma, believing that doing so could make them reallike bringing relatives back from the dead, which would not be a positive experience. In these instances, although drawing may not be possible, the lack of drawing itself prompts discussion of challenging issues which would not otherwise come up.

During one-on-one sessions, it emerged that Thomas's main concern was not the thokolosi or how it looked, but rather how he was treated at school by his classmates due to his lack of sleep. He wrote, “...they call me 'setotwane,' the one who does not sleep at night, because I sleep in class. Please auntie (name of social worker), help 
Bangwe ba ikutlwa ba le nosi ebile ba na le bodutu mo ba feletsang ba eletsa go swa. Tshwantsha o supe gore o ikutlwa jang.

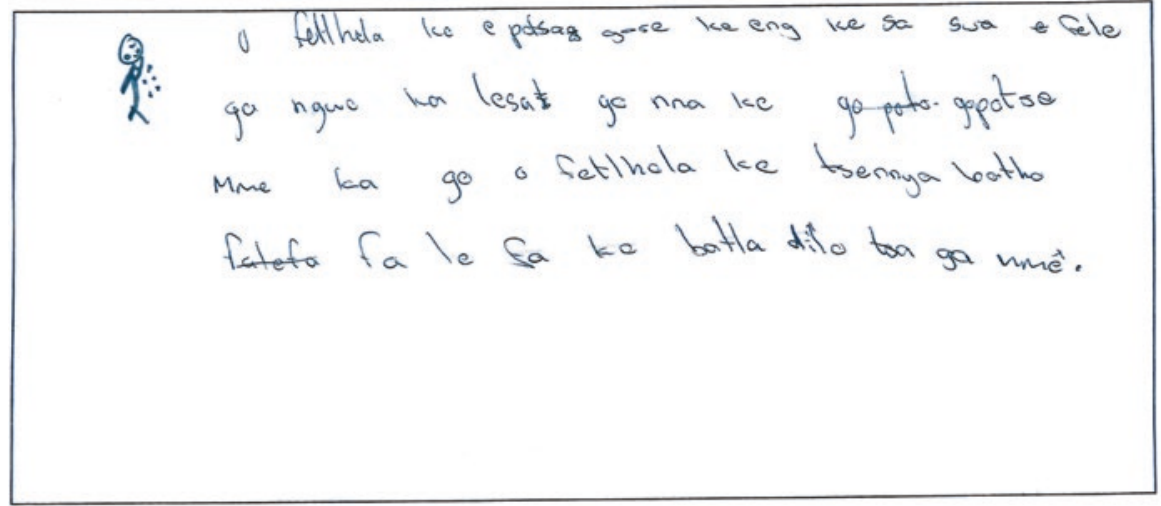

Loso ga le itlhophelwe. Ikgethele go tshela botshelo jo bo siameng.

Fig. 2.5 Peter's self-portrayal of him crying (the caption reads: "I always wonder why I cannot just die so that I stop continuously thinking about my mother."). (Reproduced with permission from Ark and Mark Trust, Botswana. Copyright @ 2021 Ark and Mark Trust. All rights reserved)

me, I do not want to be called 'setotwane."' When the social worker tried to address the thokolosi, Thomas pleaded with her just to help him sleep, believing that only his pastor could help him deal with the thokolosi.

Some participants were able to draw figures of the dead that they dreamt or thought about. In Fig. 2.6, Tracy (who also drew Fig. 2.3) drew her mother and herself again, seemingly without hands. Tracy explained that the absence of hands symbolizes helplessness because they miss each other but cannot meet and hug each other again. She also explained that they are both wearing red because they are both experiencing pain in the world of the dead and the living.

\subsubsection{Caregiver Suicide}

A number of participants drew pictures depicting the suicide of a parent or caregiver. Some had committed suicide to end the pain they were experiencing. Other times, caregivers took their own lives because they felt unable to care for family members.

Some participants described being tormented by the suicide of their parents and caregivers. For instance, 15-year-old Raymond focused his attention on the body of his uncle (Fig. 2.7). He colored the body and rope with close attention to detail, shading and giving relief to different parts. In contrast, little attention was given to the tree, which he did not give color to at all. The social worker later recounted what 


\section{Ditshwantsho tse di tshosang di tla mo dikakanyong le mo ditorong tsame dinako di ngwe. Tshwantsha/kwala o supa toro kgotsa dikakanyo tse di tshosang tse o kileng wa nna le tsone.}

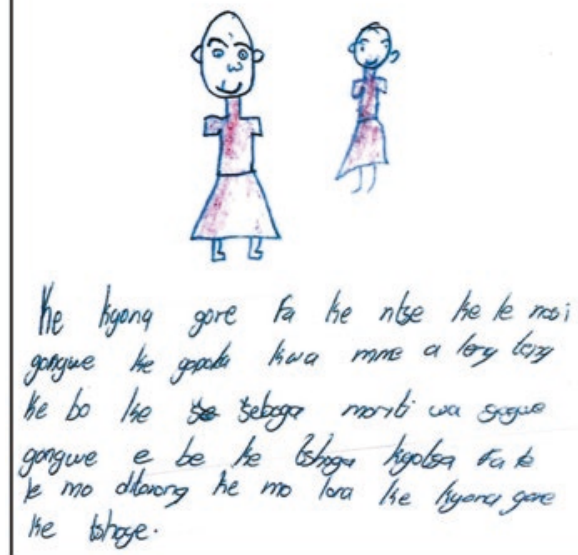

Go a thusa go dira ditshwantsho tseo mo pampiring o bo o buisanya le mongwe ka tsone.

Fig. 2.6 Tracy's depiction of seeing the dead (the caption reads: "I often see a figure of my mother when I am alone and thinking about her. Sometimes I see her in my dreams. I get scared when this happens.”). (Reproduced with permission from Ark and Mark Trust, Botswana. Copyright @ 2021 Ark and Mark Trust. All rights reserved)

Raymond had told her-that his uncle was the center of his life and that he cared deeply about him. Raymond expressed that his uncle's clothes were very vivid in his memory, and that the imagery sometimes disturbed his thinking and his concentration at school.

According to his social worker, Raymond described all the good things his uncle used to do to support him after his mother's death. He explained that after his uncle committed suicide, he had no support. He said he felt helpless and at one time attempted suicide on the same tree. He showed the social worker the scars on his neck from the failed attempt.

One participant, Thabo (age 13), drew his late mother who committed suicide (Fig. 2.8). He used the same colors in another picture of his family home burning down (Fig. 2.9). When asked to talk about the colors, such as why he drew his mother in red, he said, "...death is just like fire. It takes away life. Blood and fire are red." He also said that blue marked significant things that were problems in his life. The blue tree and the blue on the house (reminding him of the damage) were things that continued to disturb him. 


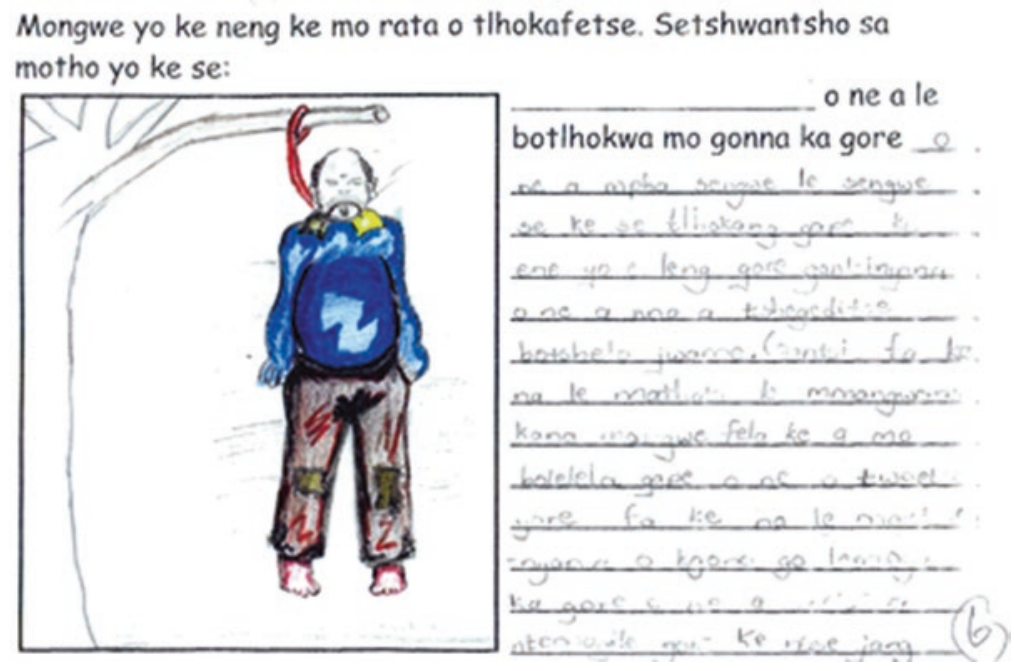

Fig. 2.7 Raymond's depiction of the suicide of his uncle (the caption reads: "My uncle had my life in his hands. He provided everything for me, I used to tell him when [my] aunt troubled me...but now he is gone."). (Reproduced with permission from Ark and Mark Trust, Botswana. Copyright (c) 2021 Ark and Mark Trust. All rights reserved)

\subsubsection{Poverty}

Many of the young people revealed their economic status through drawings, and several conveyed changes in this status after the loss of their parents. Some became poor as a result of losing a breadwinner, while others' property and inheritance were seized by older relatives, knowing that the children would be powerless to stop them. Their sudden absence of financial support led to a shortage of food, health care, clothing, and other basic needs.

The change to poorer conditions constantly reminded 13-year-old Tracy of her late mother (Fig. 2.10). She explained that the big house her mother built still exists and is used by other extended members of the family, despite cracks in the walls. She was moved to sleep in a smaller (mud) house, where she felt unsafe because the door could not be locked. According to the social worker, Tracy cried a lot when talking about this, saying, "It exposes us to risks. I want to live in my late mum's big house."

Throughout her narrations, Tracy mentioned God as her source of strength but explained that her grandmother and aunt tried to stop her from attending church, saying she would bring bad spirits into the family. This caused her some distress, as she would frequently attend church with her late mother and felt blocked from continuing this ritual and engaging with this source of support. 
Mo go botthe ba losika ba ba suleng, yo o neng a le botlhokwa thata mo go nna ke

Setshwantsho se se supa fa a thokafetseng ka teng, ka fa go nkamileng ka teng.

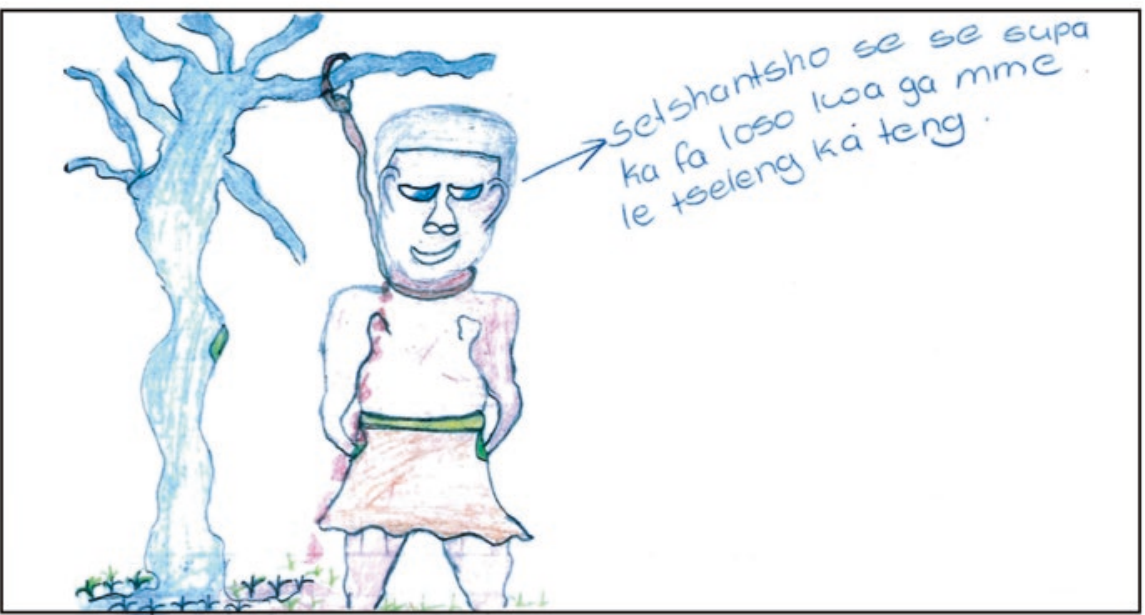

Go ntsha kutlobotlhoko ya gago ke nngwe ya ditsela tsa go e fokotsa.

Fig. 2.8 Thabo's depiction of his mother's suicide (the caption reads: "This picture shows how my mother died."). (Reproduced with permission from Ark and Mark Trust, Botswana. Copyright () 2021 Ark and Mark Trust. All rights reserved)

\subsubsection{Resources and Strategies}

Through the process of drawing and reflecting on their drawings, the participants identified several external resources that could help them manage challenges in their lives. Of these resources, relationships were cited as critical. They referred to peers at the camp, relatives, social workers, other staff at the camp, community chiefs, teachers, friends, and neighbors. Those most commonly discussed are explored below.

\subsubsection{Peers}

Peers were described as a strong source of support at the camp. The group sessions encouraged sympathy and empathy among the participants when they listened to each other talking about their drawings: "I listened to others talk about their problems. I am not the only one... We all need help." Not only did this process facilitate a greater sense of kinship, it was also described as cathartic. Leila said, “...I mean, when others shared stories about witchcraft then I felt free but not totally free. I shared some bits... and we cried together...then I was a little relieved... After listening to other children, I felt better..." Many of the participants also mentioned that 


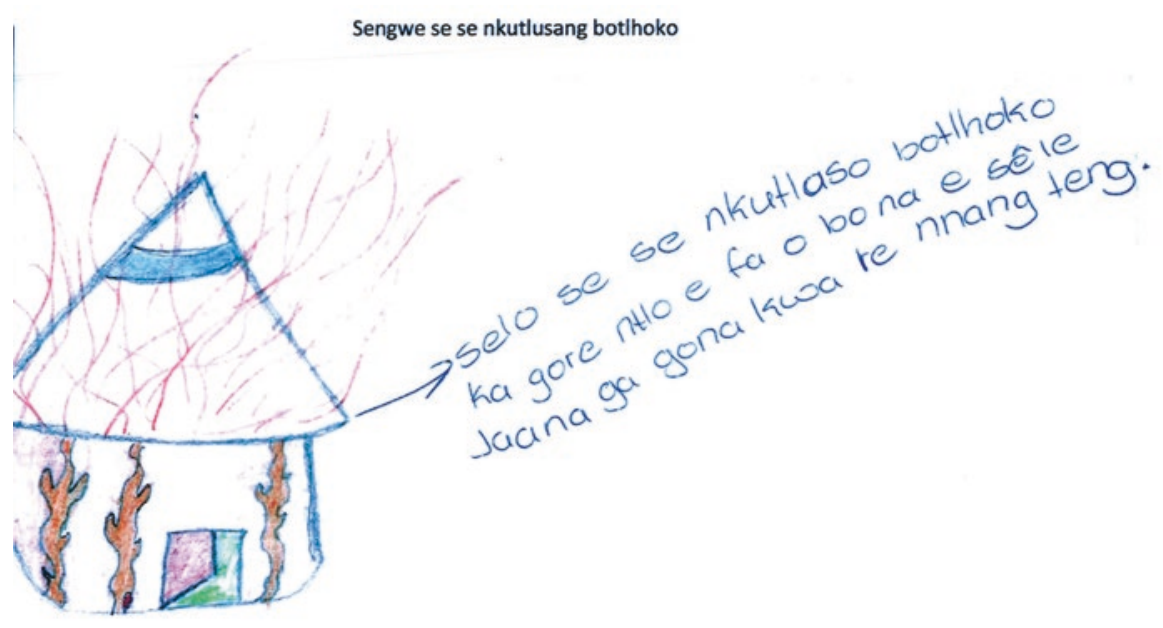

Go tshwantsha kutlobotlhoko go fokotsa botlhoko

Fig. 2.9 Thabo's depiction of his house burning down (the caption reads: "What hurts me the most is that we have no place to live. As you can see, our house is burnt down by fire."). (Reproduced with permission from Ark and Mark Trust, Botswana. Copyright (C) 2021 Ark and Mark Trust. All rights reserved)

they would continue talking to others from the camp after the end of the camp if they felt sad.

\subsubsection{Relatives}

Relatives were seen as a source of stress and a source of strength at the same time. Many of the young participants were abused by relatives yet still looked to them for support, suggesting these perceptions could come at different times: "They are not always bad"; "I can talk to them when they are happy"; "It seems I am bothering my relatives...I will not give up, sometimes they listen."

Following drawing and discussions, some suggested that a change in a relationship with caregivers could be possible: "I live with my aunt. I will tell her that I told the social worker (about the witches). She may not be happy with me. But she loves me a lot. Maybe we can talk together more about this."

\subsubsection{Social Workers}

Many of the participants described a closer connection to their social worker following the camp. Peter, who had previously expressed wishing to die, wrote, "I now have a plan. When I am in pain and need help, I would like to talk to my social 
Go nnile le diphetogo tse dintsi kwa ke nnang teng. Tshwantsha kana o kwale o supa phetogo e e go tshwentseng thata.

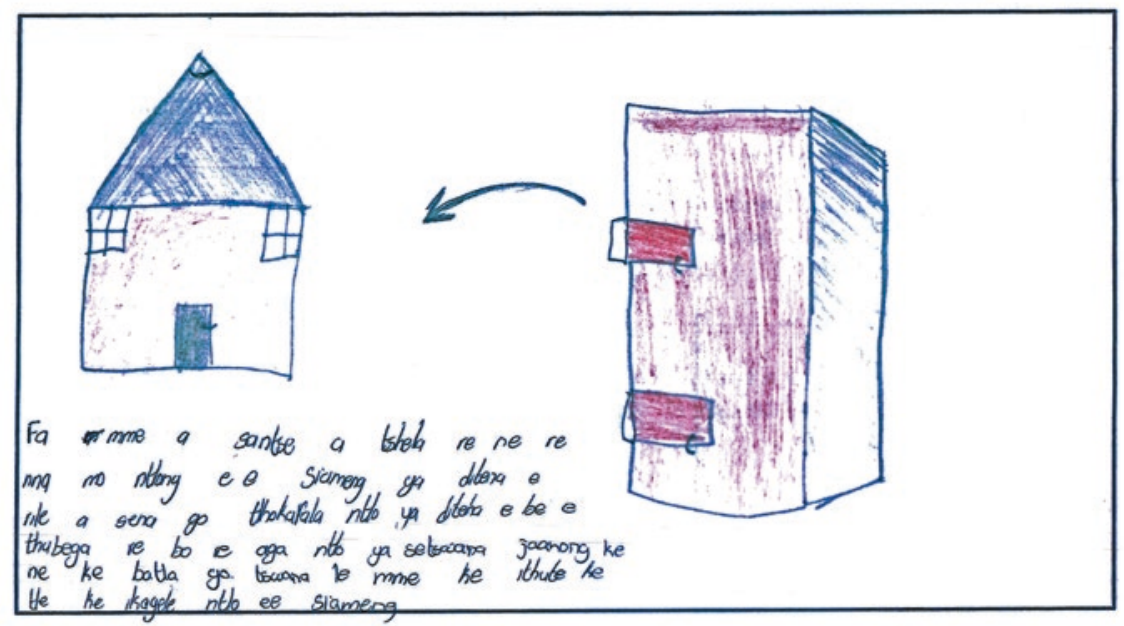

Batho ba le bantsi ba tlhaloganya ka mathata a gago, gape ba leka go go thusa.

Fig. 2.10 Tracy's depiction of the change in her housing (the caption reads: "When my mother was still alive, we had a decent home. She had built us a nice house. After her death, the house cracked and fell apart. We then built a traditional round mud house. I want to be like my mother, to get educated and build a good house for myself."). (Reproduced with permission from Ark and Mark Trust, Botswana. Copyright (C 2021 Ark and Mark Trust. All rights reserved)

worker. She is a nice person.” A greater connection with the social worker appeared to be established through the process of drawing and discussion, leading to this new source of support for the individual: "I have been very angry with uncle. I felt better after discussing this picture with the social worker. I have to do something to get more help so that the lost house is replaced...I have hope..."

\subsubsection{Community Leaders}

Traditional leaders (chiefs) were described as being helpful in resolving issues of abuse, mitigating property grabbing by relatives, and tracing absent fathers (a common issue in the region): "The chief of my village supports children... Last year he came here, with my sister's group. I think I can talk to him when I have problems. [Like] if they [caregivers] beat me again." Through drawing, the adolescents described knowing more about what they could talk to their community leaders about in order to try to receive assistance or resolve conflicts. 


\subsubsection{Community Members}

Participants also considered the community as helpful in stressful times. Some referred to neighbors who were also their relatives and expressed that they could be good sources of support. Raymond, who had attempted suicide on the same tree his uncle used, was rescued from the tree by community members. Reflecting on this incident gave him hope that there were others out there who cared about him. He said that this led him to seek help from teachers at school.

\subsubsection{Spirituality}

After drawing their experiences and describing past and ongoing challenges, some of the children described how God and going to church could help them manage these difficulties. Thomas, the one tormented by a thokolosi, believed his pastor's prayers would keep the monster at bay, while others suggested that God and being a good Christian would keep them insulated from the dangers of witches and witchcraft.

\subsection{Discussion}

Drawing, as employed in this context, appears to work well when used in conjunction with written and verbal narratives. It appears to achieve what other types of approaches could miss (Vendeville et al. 2018), such as when the participants felt unable or unwilling to bring up issues in group or individual sessions but were able to draw them. Through drawing, the participants disclosed suppressed traumatic experiences: suicide attempts, wishes to die, hallucinations, experiences at graveyards, scary dreams, beliefs and trauma connected to witches and ghosts, visits by the dead, and ongoing abuse. If used with care and skill, drawing can be a safe way of delving deeper into one's inner experience. (Rubin 2011). Not only does drawing serve as a powerful communication tool for challenging incidents, it also helps convey and release suppressed emotions (Bonoti and Misalidi 2015).

Lev-Wiesel and Liraz (2007) argue that when drawing is used before verbal narrations, it encourages children's communication of traumatic experiences. In their study, children who lived with drug-addicted fathers drew scary eyes, undernourished skeletal fathers, and instruments connected to drug use. After drawing, these children were able to describe their drawings verbally, indirectly conveying their traumatic experiences, while the control group who did not draw had difficulty expressing similar emotionally provoking experiences. However, some have argued that drawing becomes easier for individuals to engage in if they follow narrative approaches first (Farokhi and Hashemi 2011; Malindi and Theron 2011). For instance, when other therapeutic approaches like group discussions, drama, or individual therapy are used before drawings, they prepare children to freely use 
drawings to express hidden emotions that they may struggle to convey (Dalley and Case 2014). Indeed, when first devising the Balekane EARTH program, Thamuku and Daniel (2013) explored different therapeutic approaches and noted that in the initial group work, the participants tended to prefer to discuss their general social challenges, and that this gentle introduction helps to softens their "hard shell" of grief. Once this shell was opened, it permitted access to more challenging issues, which can be reached through the use of drawings (Thamuku and Daniel 2013). This reflects the findings of others who have emphasized that effective therapy is cumulative, starting with the less sensitive issues before progressing to those that are more sensitive; the foundational steps help participants to open up slowly (Bonoti and Misalidi 2015; Farokhi and Hashemi 2011; Thamuku and Daniel 2013).

In the present study, we established that drawing was introduced on the seventh day of therapy, after several narrative sessions. But narratives were also used after the drawing experience to discuss what was in the drawings. Therefore, the EARTH program seems flexible in the sequence of verbal narratives and drawing. Most of the participants were able to draw, narrate, and explain painful emotions connected to traumatic experiences, but the order and unlocking mechanism behind these steps varied among the participants; some drew in the beginning in order to be able to talk about an issue, while others struggled to draw if issues were not broached and worked through verbally first. It is possible that those who only wrote narratives in their workbooks could have been asked to go back and draw after verbal therapy sessions with their social workers. This underscores the importance of using drawing as an additional and complementary tool in therapeutic programs and encourages using it flexibly with discussion.

The theory of salutogenesis provides a framework to systematically and critically examine the health-promoting benefits of drawing. In this discussion, we reflect on the key findings from the drawings and the experiences of the drawing process using the concepts of comprehensibility, manageability, and meaningfulness.

\subsubsection{Comprehensibility}

During group narratives about their drawings, hearing the stories of the other adolescents helped participants understand their own experiences. For example, Leila helped others feel able to express their experiences with witchcraft. One of the social workers described how, in one group session, the crying of one participant gave permission for others to cry and release suppressed pain. These examples show that adolescents were able to connect and deal with past terrors. Narratives on drawings enabled them to comprehend that their own feelings are "normal" and okay to express - that others have similar pain (Anolak et al. 2018). Given the widespread beliefs about witchcraft that persist in sub-Saharan Africa, Leila's story is, unfortunately, not uncommon (Mills 2018). 
Our analysis of the participants' drawings and their accompanying narratives indicates that the the comprehension of their problems was influenced by how they experienced loss, grief, and trauma; by the availability of resources around them; and by their opportunities to navigate to access those resources. In their narratives, some expressed that they had already accessed help-for example, seeing social workers. Others started taking action by talking to friends and other adults at the camp.

Regardless of their extreme emotional challenges, the participants seemed to have an understanding that their situations were resolvable. Initially, some appeared more helpless and others were more optimistic, while many moved back and forth between pain and progress to health through the 14 days of the camp. In the case of the latter, the SOC was not experienced as a continuum, as reflected in Fig. 2.1, but rather as a dynamic movement between comprehension, stress, and well-being. Most young people seemed to go back and forth between their challenges and strategies to get back home and use resources. Their hope was linked both to resources they had previously known were available and to ones they had newly learned about. Some had attempted to use resources such as family, friends, and professional services like social workers before the camp; although these young people were still experiencing the same challenges, they would not give up. Their drawings showed that the camp experience strengthened them to persist or to try again in other ways. Many believed they could solve the intangible with the abstract-for example, addressing witchcraft experiences with their belief in God.

\subsubsection{Manageability}

When people show hope, and when their perceptions of stressors are tied with the availability of resources, it indicates the manageability of situations, hence movement toward health (Darkwah et al. 2017). In this study, drawing helped to activate positive internal resources, with the participants often saying that the drawing process itself gave them a sense of relief and release. Some mentioned that while drawing their traumatic experiences, they felt pain, missed their late parents, cried, and felt fear, but at the end of the process they felt a relief from their hearts. This fits with an understanding of the cathartic properties of drawing (Bonoti and Misalidi 2015).

Art and writing has empowering effects (Garista et al. 2019; Thamuku and Daniel 2013), and this was reflected in our findings, where participants consistently reflected on sources of support. They noted a network of resources: peers at the camps, relatives, camp and local social workers, teachers, traditional leaders, neighbors, and the broader community. Writing and talking about such strategies appeared to support them as they drew hurtful experiences. In particular, peer and group work helped them realize that they shared experiences of loss, fear, abuse, and pain with others. A sense of support and greater manageability materialized when others were seen to cope with their difficulties. 
Some participants were already aware of resources and had used them before the camp, but through drawing they became aware of additional resources available to them. They also gained knowledge about different ways to use the resources they had tried before, such as getting support from caregivers when relationships were strained.

\subsubsection{Meaningfulness}

Drawing helped the young people to make sense of the distressing experiences related to the loss of parents and caregivers, and, once clarified, they became active participants in the process to discover solutions to their challenges. Their motivation to participate in sessions and take action was linked to the existing resources that the program seemed to make possible for them to access. The social workers reported a positive change in those who were withdrawn-even in those who were initially wishing to die. Many participants became optimistic about their futures by the end of the camp and described positive next steps and longer-term plans. The young adults who participated were examples of this positive change, having become successful and active members of their communities. These ideas are further explored in the final chapter of this volume (see Chap. 21), which suggests a theoretical framework for conceptualizing some of these meaning-making dynamics.

\subsection{Conclusion}

For adolescents in stressful situations, drawing is a tool that can help them move toward greater health and well-being. Using a salutogenic lens, our findings reveal that drawing can be beneficial in helping young people communicate complex emotional stressors and map different resources that they have around them. Drawing has empowering effects, promotes creativity, and can help young people visualize strategies to manage their traumatic experiences.

However, we found that when young people experience trauma, they do make efforts to access existing resources, even before therapy, indicating that they should not be pathologized as only weak, stressed, or depressed. Therapeutic programs should embrace and build on these existing resources and identify those that may be present but troubled or unused. Drawing presents an important tool for such discovery and communication, both for the individual and the practitioner. 


\section{References}

Anolak, H., Watt, B., \& Thornton, C. (2018). Guided imagery and music (GIM) combined with music, drawing and narrative (MDN) as an intervention for reducing perinatal anxiety. Women and Birth, 31, S30-S31. https://doi.org/10.1016/j.wombi.2018.08.095.

Antonovsky, A. (1996). The salutogenic model as a theory to guide health promotion. Health Promotion International, 11(1), 11-18. https://doi.org/10.1093/heapro/11.1.11.

Attride-Stirling, J. (2001). Thematic networks: An analytic tool for qualitative research. Qualitative Research, 1(3), 385-405. https://doi.org/10.1177/146879410100100307.

Bonoti, F., \& Misalidi, P. (2015). Social emotions in children's human figure drawings: Drawing shame, pride and jealousy. Infant and Child Development, 24(6), 661-672.

Braun-Lewensohn, O., Idan, O., Lindström, B., \& Margalit, M. (2017). Salutogenesis: Sense of coherence in adolescence. In B. M. Maurice, S. Shifra, M. E. F. Georg, J. M. Bauer, M. P. Jürgen, et al. (Eds.), The handbook of salutogenesis (pp. 123-136). New York: Springer.

Campbell, C., Skovdal, M., Mupambireyi, Z., \& Gregson, S. (2010). Exploring children's stigmatisation of AIDS-affected children in Zimbabwe through drawings and stories. Social Science \& Medicine, 71(5), 975-985. https://doi.org/10.1016/j.socscimed.2010.05.028.

Campbell, C., Andersen, L., Mutsikiwa, A., Madanhire, C., Skovdal, M., Nyamukapa, C., et al. (2015). Re-thinking children's agency in extreme hardship: Zimbabwean children's draw-andwrite about their HIV-affected peers. Health \& Place, 31, 54-64. https://doi.org/10.1016/j. healthplace.2014.09.008.

Cluver, L., Gardner, F., \& Operario, O. (2007). Psychological distress amongst AIDS-orphaned children in urban South Africa. Journal of Child Psychology and Psychiatry, 48(8), 755-763. http://onlinelibrary.wiley.com/store/10.1111/j.1469-7610.2007.01757.x/asset/j.1469-7610 .2007.01757.x.pdf? $v=1 \& \mathrm{t}=$ jb6gxz29\&s=502102d3302afc31e8af9b99cdffbd48e93105ef.

Dalley, T., \& Case, C. (2014). The handbook of art therapy. East Sussex: Routledge.

Daniel, M., Apila, H. M., Bjorgo, R., \& Lie, G. T. (2007). Breaching cultural silence: Enhancing resilience among Ugandan orphans. Ajar-African Journal of Aids Research, 6(2), 109-120. https://doi.org/10.2989/16085900709490405.

Darkwah, E., Asumeng, M., \& Daniel, M. (2017). Caring for "parentless" children: An exploration of work stressors and resources as experienced by caregivers in children's homes in Ghana. International Journal of Child, Youth and Family Studies, 8(2), 59-89. https://doi. org/10.18357/ijcyfs82201717850.

Deininger, K., Garcia, M., \& Subbarao, K. (2003). AIDS-induced orphanhood as a systemic shock: Magnitude, impact, and program interventions in Africa. World Development, 31(7), 1201-1220.

Elfassi, Y., Braun-Lewensohn, O., Krumer-Nevo, M., \& Sagy, S. (2016). Community sense of coherence among adolescents as related to their involvement in risk behaviors. Journal of Community Psychology, 44(1), 22-37. https://doi.org/10.1002/jcop.21739.

Farokhi, M., \& Hashemi, M. (2011). The analysis of children's drawings: Social, emotional, physical, and psychological aspects. Procedia-Social and Behavioral Sciences, 30, 2219-2224.

Garista, P., Pocetta, G., \& Lindström, B. (2019). Picturing academic learning: Salutogenic and health promoting perspectives on drawings. Health Promotion International, 34(4), 859-868.

Heath, M. A., Donald, D. R., Theron, L. C., \& Lyon, R. C. (2014). AIDS in South Africa: Therapeutic interventions to strengthen resilience among orphans and vulnerable children. School Psychology International, 35(3), 309-337. https://doi.org/10.1177/0143034314529912.

Heegaard, M. E. (1996). When someone very special dies: Children can learn to cope with grief. Minneapolis, MN: Woodland Press.

Jellesma, F. C., Rieffe, C., Terwogt, M. M., \& Kneepkens, C. M. F. (2006). Somatic complaints and health care use in children: Mood, emotion awareness and sense of coherence. Social Science \& Medicine, 63, 2640-2648. https://doi.org/10.1016/j.socscimed.2006.07.004. 
Katisi, M., Jefferies, P., Dikolobe, O., Moeti, O., Brisson, J., \& Ungar, M. (2019). Fostering resilience in children who have been orphaned: Preliminary results from the Botswana Balekane EARTH program. Child \& Youth Care Forum, 48, 585-601.

Lev-Wiesel, R., \& Liraz, R. (2007). Drawings vs. narratives: Drawing as a tool to encourage verbalization in children whose fathers are drug abusers. Clinical Child Psychology and Psychiatry, 12(1), 65-75. https://doi.org/10.1177/1359104507071056.

Løndal, K. (2010). Children's lived experience and their sense of coherence: Bodily play in a Norwegian after-school programme. Child Care in Practice, 16(4), 391-407. https://doi.org/1 $0.1080 / 13575279.2010 .498414$.

Malindi, M., \& Theron, L. (2011). Drawing on strengths: Images of ecological contributions to street child resilience. In L. C. Theron, C. Mitchell, J. Stuart, \& A. Smith (Eds.), Picturing research drawings as visual methodology (pp. 105-118). Rotterdam: Sense Publishers.

Mayer, C. H., \& Krause, C. (2011). Promoting mental health and salutogenesis in transcultural organizational and work contexts. Taylor \& Francis Online. https://doi.org/10.3109/0954026 1.2011.636549.

Meissner, R. J., Ferguson, J., Otto, C., Gretschel, P., \& Ramugondo, E. (2017). A play-informed, caregiver-implemented, home-based intervention for HIV-positive children and their families living in low-income conditions in South Africa. World Federation of Occupational Therapists Bulletin, 73(2), 83-87. https://doi.org/10.1080/14473828.2017.1375068.

Mills, J. (2018). Witchcraft, witches, and violence in Ghana. Taylor \& Francis Online. https://doi. org/10.1080/00083968.2018.1439280.

Mittelmark, M. B. (2017). Introduction to the handbook of salutogenesis. The Handbook of Salutogenesis (pp. 3-5). New York: Springer.

Mittelmark, M. B., \& Bull, T. (2013). The salutogenic model of health in health promotion research. Global Health Promotion, 20(2), 30-38. https://doi.org/10.1177/1757975913486684.

Nammontri, O., Robinson, P. G., \& Baker, S. R. (2013). Enhancing oral health via sense of coherence: A cluster-randomized trial. Journal of Dental Research, 92(1), 26-31. https://doi. org/10.1177/0022034512459757.

Pifalo, T. (2007). Jogging the cogs: Trauma-focused art therapy and cognitive behavioral therapy with sexually abused children. Art Therapy, 24(4), 170-175. https://doi.org/10.1080/0742165 6.2007.10129471.

Ray, C., Suominen, S., \& Roos, E. (2009). The role of parent's sense of coherence in irregular meal pattern and food intake pattern of children aged 10-11 in Finland. Journal of Epidemiology \& Community Health, 63(12). https://doi.org/10.1136/jech.2008.085100.

Rubin, J. A. (2011). The art of art therapy: What every art therapist needs to know. London: Routledge.

Schenk, K. D. (2009). Community interventions providing care and support to orphans and vulnerable children: A review of evaluation evidence. AIDS Care, 21(7), 918-942. http://www. tandfonline.com/doi/pdf/10.1080/09540120802537831?needAccess=true.

Skovdal, M. (2012). Pathologising healthy children? A review of the literature exploring the mental health of HIV-affected children in sub-Saharan Africa. Transcultural Psychiatry, 49(3-4), 461-491. https://doi.org/10.1177/1363461512448325.

Skovdal, M., \& Daniel, M. (2012). Resilience through participation and coping-enabling social environments: The case of HIV-affected children in sub-Saharan Africa. African Journal of AIDS Research, 11(3), 153-164. https://doi.org/10.2989/16085906.2012.734975.

Strebel, A. (2004). The development, implementation and evaluation of interventions for the care of orphans and vulnerable children in Botswana, South Africa and Zimbabwe: A literature review of evidence-based interventions for home-based child-centred development. Cape Town: HSRC Publishers.

Thamuku, M., \& Daniel, M. (2013). Exploring responses to transformative group therapy for orphaned children in the context of mass orphaning in Botswana. Death Studies, 37(5), 413-447. https://doi.org/10.1080/07481187.2012.654594. 
Toska, E., Gittings, L., Hodes, R., Cluver, L. D., Govender, K., Chademana, K. E., et al. (2016). Resourcing resilience: Social protection for HIV prevention amongst children and adolescents in Eastern and Southern Africa. African Journal of AIDS Research, 15(2), 123-140. https://doi. org/10.2989/16085906.2016.1194299.

Ugurlu, N., Akca, L., \& Acarturk, C. (2016). An art therapy intervention for symptoms of posttraumatic stress, depression and anxiety among Syrian refugee children. Vulnerable Children and Youth Studies, 11(2), 89-102. https://doi.org/10.1080/17450128.2016.1181288.

UNAIDS. (2019). Global HIV \& AIDS statistics—2019 fact sheet. Available at https://www. unaids.org/en/resources/fact-sheet.

Vendeville, N., Blanc, N., \& Brechet, C. (2018). Tears for girls and teeth for boys: The influence of gender on children's depiction of sadness and anger in their drawings. Educational Psychology, 1-18. https://doi.org/10.1080/01443410.2018.1461810.

Wakhweya, A., Dirks, R., \& Yeboah, K. (2008). Children thrive in families: Family-centred models of care and support for orphans and other vulnerable children affected by HIV and AIDS. AIDS JLICA.

Xiaoming, L., Peilian, C., Lorraine, S., Lucie, C., \& Bonita, S. (2015). Psychological resilience among children affected by parental HIV/AIDS: A conceptual framework. Health Psychology and Behavioral Medicine, 3(1), 217-235. https://doi.org/10.1080/21642850.2015.1068698.

Open Access This chapter is licensed under the terms of the Creative Commons AttributionNonCommercial-NoDerivatives 4.0 International License (http://creativecommons.org/licenses/ by-nc-nd/4.0/), which permits any noncommercial use, sharing, distribution and reproduction in any medium or format, as long as you give appropriate credit to the original author(s) and the source, provide a link to the Creative Commons license and indicate if you modified the licensed material. You do not have permission under this license to share adapted material derived from this chapter or parts of it.

The images or other third party material in this chapter are included in the chapter's Creative Commons license, unless indicated otherwise in a credit line to the material. If material is not included in the chapter's Creative Commons license and your intended use is not permitted by statutory regulation or exceeds the permitted use, you will need to obtain permission directly from the copyright holder.

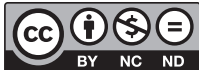

